\title{
As práticas dos Métodos Pedagógicos para criança com TEA
}

\author{
The practices of Pedagogical Methods for children with ASD \\ Las prácticas de los métodos pedagógicos para niños con TEA
}

Recebido: 27/10/2021 | Revisado: 02/11/2021 | Aceito: 04/11/2021 | Publicado: 19/12/2021

Marcilene Nunes Abreu

ORCID: https://orcid.org/0000-0001-7010-927X

Faculdade Martha Falcão Wyden, Brasil

E-mail: marcileneabreu.psico@gmail.com

Samara de Oliveira Lima

ORCID: https://orcid.org/0000-0001-9218-1248 Centro Universitário FAMETRO, Brasil

E-mail:samaradol_mara@hotmail.com

Marilene Castilho de Almeida

ORCID: https://orcid.org/0000-0003-3959-1883 Centro Universitário FAMETRO, Brasil

E-mail: marilene_castilho@hotmail.com

Sabrina de Oliveira Marques

ORCID: https://orcid.org/0000-0001-7062-6517

Faculdade Martha Falcão Wyden, Brasil

E-mail: ipsi.sabrina@gmail.com

Sanara Macedo Sousa

ORCID: https://orcid.org/0000-0002-6799-8704 Centro Universitário UNINORTE, Brasil

E-mail: sanaranara@hotmail.com

Rossivaldo Duarte de Lima

ORCID: https/orcid.org/00000-0002/9395-6997 Faculdade Martha Falcão Wyden, Brasil

E-mail: rossivaldolima@hotmail.com

Jorge Victor Araújo Gonçales

ORCID: https//orcid.org/0000-0003-0810-3808

Universidade Luterana de Manaus, Brasil

E-mail: jorge.gleice10@gmail.com

Israel Vitor Paulino de Carvalho

ORCID: https://orcid.org/0000-0002-3315-0377

Universidade Luterana de Manaus, Brasil

E-mail: israelvitor19@gmail.com

Gleice Pereira Lopes

ORCID: https://orcid.org/0000-0002-4969-9491

Faculdade Boas Novas, Brasil

E-mail: hector.mallu38@gmail.com

\begin{abstract}
Resumo
O presente artigo tem como objetivo apresentar as possíveis Etapas do Transtorno do Espectro Autista (TEA), as Práticas Pedagógicas, e os Métodos para desenvolvimento e Intervenção precoce da criança com TEA. Ressaltando a importância do Psicopedagogo (a) no processo dessas práticas e da intervenção DUSNST \& BRUDER (2002), desmitificando o imaginário social, o qual descreve que tal criança não pode se desenvolver, e da não existência de recursos/ferramentas a serem usadas em seu favor. Nesse envolto, a pesquisa se caracteriza como bibliográfica, com caráter exploratório. Evidenciando que o reconhecimento do TEA, bem como as práticas pedagógicas e os métodos, são determinantes para um desenvolvimento integral e ações significativas na vida de uma criança com TEA, não esquecendo que a família é peça fundamental para a inclusão da criança com TEA em todos os âmbitos da sociedade. Com isso, buscamos responder por meio dessa pesquisa, questionamentos relacionados a ausência de recursos, para evoluir a criança com Transtorno do Espectro do Autismo (TEA) no âmbito educacional.
\end{abstract}

Palavras-chave: TEA; Prática pedagógicas; Métodos e desenvolvimento.

\begin{abstract}
This article aims to present the possible Stages of the Autistic Spectrum Disorder (ASD), the Pedagogical Practices, and the Methods for the early development and Intervention of the child with ASD. Emphasizing the importance of the Psychopedagogist (a) in the process of these practices and the DUSNST \& BRUDER (2002) intervention, demystifying the social imaginary, which describes that such a child cannot develop, and the non-existence of resources/tools to be used in your favor. In this context, the research is characterized as bibliographical, with an
\end{abstract}


exploratory character. Evidencing that the recognition of the ASD, as well as the pedagogical practices and methods, are crucial for a comprehensive development and significant actions in the life of a child with ASD, not forgetting that the family is a fundamental part for the inclusion of the child with ASD in all the spheres of society. Thus, we seek to answer, through this research, questions related to the lack of resources, to evolve the child with Autism Spectrum Disorder (ASD) in the educational sphere.

Keywords: ASD; Pedagogical practices; Methods and Development.

\section{Resumen}

Este artículo tiene como objetivo es presentar las posibles Etapas del Trastorno del Espectro Autista (TEA), las Prácticas Pedagógicas y los Métodos para el desarrollo temprano e Intervención del niño con TEA. Destacando la importancia del Psicopedagogo (a) en el proceso de estas prácticas y la intervención de DUSNST \& BRUDER (2002), desmitificando el imaginario social, que describe que tal niño no puede desarrollarse, y la inexistencia de recursos / herramientas para ser usado a tu favor. En este contexto, la investigación se caracteriza por ser bibliográfica, con carácter exploratorio. Evidenciar que el reconocimiento del TEA, así como las prácticas y métodos pedagógicos, son cruciales para un desarrollo integral y acciones significativas en la vida de un niño con TEA, sin olvidar que la familia es parte fundamental para la inclusión del niño. con TEA en todos los ámbitos de la sociedad. Con eso, buscamos dar respuesta, a través de esta investigación, preguntas relacionadas con la falta de recursos, para hacer evolucionar al niño con Trastorno del Espectro Autista (TEA) en el ámbito educativo.

Palabras clave: TEA; Prácticas pedagógicas; Métodos y desarrollo.

\section{Introdução}

O Transtorno do Espectro do Autismo (TEA) é um termo que contempla dentre outras manifestações, o autismo. Nos dias atuais é muito utilizado, contudo, requer um conhecimento mais específico sobre suas etapas, bem como as ferramentas/recurso disponíveis para se evoluir uma criança com TEA. Com essas prerrogativas, o artigo tem como objetivo apresentar as possíveis Etapas do Transtorno do Espectro Autista (TEA), as Práticas Pedagógicas, e os Métodos para desenvolvimento e Intervenção precoce da criança com TEA. Assim, permite a compreensão do Transtorno e dos métodos evolutivos tanto para a sociedade,como também para a comunidade educacional, esclarecendo que tais instituições educacionais devem conhecer, incluir no mais amplo sentido da palavra a criança com TEA. Para fundamentação da pesquisa, nos debruçamos em leituras de aportes teóricos que ampliam a discussão da temática e abordam a compreensão dos aspectos importantes às etapas do TEA e a possível Pratica Pedagógica. Vale ressaltar que esta pesquisa é um recorte do Trabalho de Conclusão do Curso (TCC), construído pelas autoras desse trabalho. Espera-se com a pesquisa evidenciar alguns recursos/ferramentas, conhecimento das etapas do TEA, bem como a compreensão dos aspectos inerentes a pessoa com TEA, compressão e acolhimento determinantes no seu processo evolutivo enquanto SER. Diante do exposto, o presente artigo tem enquanto relevância cientifica a intenção de contribuir para a compreensão e aprofundamento do fenômeno investigado e a construção de novos conhecimentos. Enquanto acadêmico contribuir para o conhecimento das práticas pedagógicas e métodos para construção do desenvolvimento da criança com TEA

\section{Fundamentação Teórica}

\subsection{Conhecendo as etapas do Transtorno do Espectro Autista (TEA)}

\subsubsection{Breve Histórico}

A palavra autismo vem do grego "autos" que significa "próprio", possui auto grau de concentração consigo mesmo, o mesmo aparece nos três primeiros anos de vida e acomete cerca um (1) a cada cento e dez (110) de acordo com a o CDC (Center ofDeseasesControlandPrevention) sendo quatro vezes mais comum no sexo masculino do que no feminino. Independente da raça, etnia ou classe social, qualquer família pode vir a ser acometida pelo TEA.

O termo autismo foi usado pela primeira vez pelo psiquiatra suíço Eugen Bleuler, este o descreve como um grupo de traços relacionado à esquizofrenia, anos depois o psiquiatra austríaco Leo Kanner, por meio de pesquisas em um grupo de crianças, pôde perceber que tais traços, apareciam na primeira infância, respondendo de maneiras incomuns ao ambiente. No 
mesmo ano das pesquisas de Leo, Hans Asperger, também psiquiatra austríaco, observou pelo padrão de comportamento e habilidades, tais sintomas ocorriam principalmente em meninos, o mesmo descrevia essas crianças como pequenos professores, pois sua habilidade com tais temas era discorrida detalhadamente, Asperger (1980) foi considerado como um dos pioneiros dos estudos do Autista a partir da década de 1980, (Asperger 1991, p. 37-92).

Após muitos anos de pesquisas e estudos, em 1970 através da psiquiatra inglesa LornanWing, mãe de uma criança autista, cunhou o termo síndrome de Aspeger, referindo-se ao psiquiatra Hans Asperger, o trabalho dessa psiquiatra revolucionou o mundo do autista, pois foi uma das maiores e mais importantes pesquisas na relação do mundo autista (Gillberg \& Gillberg, 1989).

\subsubsection{Etiologia}

Várias teorias foram propostas para determinar qual a origem do TEA, no entanto, não é concebida qualquer etiologia específica, por se tratar de uma perturbação complexa em que nenhuma pessoa é igual a outra, logo, o mais provável, é que esta perturbação seja originada por múltiplos fatores (Carr, 2006; Zager et al.,2009). Das teorias que foram surgindo estas se dividiram em três: as teorias psicogênicas, as teorias biológicas e as teorias cognitivas.

Teorias psicogênicas: mais predominante nos anos 50 e 60 , foram uma das primeiras e principais explicações para o TEA, e sugerem que este é um distúrbio emocional cuja origem se encontra no ambiente próximo da criança, não decorrendo de uma perturbação biológica (as crianças nascem "normais"), e traduzindo-se numa resposta desadaptada a um ambiente desagradável, mais do que um déficit inato (Garcia \& Rodriguez 1993). Como tal, a criança refugia-se no seu mundo em resposta ao tratamento frio e obsessivo que recebe do ambiente em que está inserida.

Considerou que as singularidades psicológicas dos pais das crianças com autismo se traduziam em relações distorcidas e patológicas com os seus filhos, e estavam na origem da síndrome autista [...] [Além disso], interpretava o autismo predominantemente como uma perturbação emocional." (Marques1998, p. 44).

Pode-se descrever que a teoria psicogenética, desenvolve a tese que uma mãe fria sem afeto, permitirá que tal criança desenvolva o TEA o antigo autismo, já que o mesmo devido sua falta de ação afetiva, segundo a teoria acima descrita, durante o desenvolvimento dessa criança, constantemente recebia resposta desadaptava em relação ao afeto. Devido essa teoria de psicogenética, em relação ao TEA, nota-se que por meios de estudos na época, efeito não muitos positivos em relação as pessoas responsáveis por essas crianças com o TEA, pois os mesmos se sentiam culpados pela falta de afetividade em relação a essas crianças.

As teorias biológicas: defendem que as teorias clínicas do TEA, refletem problemas de neurológicos, pois através de estudos e pesquisas, verificou-se por meio da associação da criança com autismo na época, que TEA, veio associado através de vários distúrbios biológicos como: rubéola pré-natal, paralisia cerebral, meningite e outros, e devido a isso o TEA, resulta também de perturbações do sistema nervoso central, o qual afeta a linguagem, o cognitivo e o intelectual. Mesmo com tantos estudos e pesquisas pelo qual levaram a teoria biológica afirmarem que o TEA, é resultante de fatores biológicos, pode-se descrever que dentro dessa teoria biológica, há evidências de outra teoria a respeito, como a questão genética, porém mesmo com tantas afirmações genéticas para o TEA, antigo autismo, a mesma não se tornou perfeita.

[...] apesar de ter vindo a ser detectada uma grande variedade de anomalias genéticas em indivíduos com perturbações do espectro do autismo, a forma de como essa anomalia afeta o desenvolvimento cerebral ainda não é conhecida. (Marques 1998, p. 53).

Teorias psicológicas: tal teoria segundo os últimos trinta anos tem se sobrepondo em relação às outras teorias, o autor Marques (1998), atribuiu a não informação do TEA, em relações as informações verbais, ao quais as recebiam de forma neutra, sem significação, pois tais respostas estereotipadas, resultado de testes cognitivos, permitiram descrever a representação dessa 
criança como representação mental inferior, causando assim dificuldades de aprendizagem. Os autistas são, assim, incapazes de extrair regras ou de estruturar experiências tanto nos domínios verbal como não verbal, o que torna compreensível a sua notória dificuldade em realizar tarefas orientadas por leis complexas como a linguagem e as interações sociais." (Marques, 1998, p. 60).

Segundo autor acima citado nota-se a dificuldade da criança com autismo colocar em ordem as informações, tanto na questão de regras quanto de organização, pois a mesma devido à dificuldade de processamento neural apresenta concentradas dificuldades nessas tarefas.

\subsubsection{Definição do Manual Diagnóstico e Estatístico de Distúrbios Mentais (DSM) de I a V.}

O Manual Diagnóstico e Estatístico de Distúrbios Mentais (DSM), teve sua publicação do ano de 1952 onde o DSM-I continha 130 páginas e 106 categorias de desordens mentais, o qual consistia em revisar as séries de doenças relacionadas a doenças mentais, o DSM-II foi publicado em 1968, com 134 páginas e 182 desordens mentais, eram declarados com imagens de grandes conflitos, de efeitos de más adaptações, no DSM III foi publicado em 1980 com 494 páginas e 265 desordens mentais, foi por meio do DSM-III, que internacionalmente veio a revolução da psiquiatria, pois em 1987 o DSM-III retirou algumas categorias e foram colocadas outras, sendo atualizada com 494 páginas e 265 doenças mentais.

Após alguns anos os DSM's tiveram alguns avanços para a medicina, pois em 1994 veio o DSM-IV com 886 páginas, 297 "transtornos", e em relação ao Transtorno Autista, podem-se descrever suas variações, que é chamado de: Autismo infantil precoce, Autismo da Infância ou Autismo de Kanner, enquadrando-se segundo o DSM-IV alguns transtornos tais quais: o Autismo Clássico, Transtorno Desintegrativo da Infância, Transtorno Global do Desenvolvimento não Específico e as Síndromes de Aspeger e Rett.

No ano de 2013, especificamente no dia 18 de maio de 2013, foi publicado pelo DSM-V o novo Manual Diagnóstico e Estatístico de Transtornos Mentais da Associação Psiquiátrica Americana, resultado de dose anos de estudo, por meios de pesquisas de campo, realizado por centenas de profissionais, permitindo assim nova classificação, e reformulação e exclusão de diagnósticos, como no lugar de Transtorno Autista (DSM-V), ficou o TEA. Essa reformulação do DSM-V, permitiu a o entendimento desses transtornos, ao quais de forma individual, os mesmos tinham seus próprios diagnósticos segundo o DSMIV, entendendo que as Síndromes acima citadas, fazem parte do TEA, saindo apenas a Síndrome de Rett, pois tal Síndrome não faz parte dos critérios do TEA, pois tem uma entidade própria, diferentemente do TEA, caracterizada pela TEA 299.00 (F 840).

Com o DSM-V publicado no ano de 2013, veio o aparecimento da nova nomenclatura como: TEA, permitindo a facilitação do diagnóstico e desenvolvimento dessa criança de forma clara e objetiva, tanto para os profissionais da saúde, pais, assistentes sociais, pessoas relacionadas a essa síndrome e professores, e assim a redução do TEA em três: leve, moderada e severa descrita abaixo:

Leve: Nível um (1), a mesma "exige apoio", em relação à comunicação social, na interação social, mesmo fazendo conversações com outras pessoas de forma falhadas, pois não há entendimento. No comportamento restrito e repetitivo: problemas para organização e planejamento, inflexibilidade do comportamento, dificuldade em trocar de atividades e obstáculos de independência.

Moderado: Nível dois (2), a mesma "exige apoio substancial", e na relação da comunicação social verbal e nãoverbal, a mesma possui graves déficits nas habilidades de comunicação social, dificuldade de iniciar interação social, dificuldade de abrirem conversações com outras pessoas e sua comunicação não-verbal acentuadamente estranha, todas essas características possuem níveis Em relação ao comportamento restrito e repetitivo, há dificuldade de lidar com as mudanças das 
pessoas, , os comportamentos restritos e repetitivos aparecem com frequência, sobrem e tem dificuldades de mudar focos ou ações.

Severo: Nível três (3), "exige apoio muito substancial”, e em relação à comunicação social há prejuízos graves de funcionamento em relação à comunicação social verbal e não-verbal, e na relação da interação social, a grande limitação em dar início em conversações. Na relação do comportamento restrito e repetitivo, o comportamento é inflexível, extrema dificuldade em lidar com mudanças, seu comportamento restrito e repetitivo interfere completamente no seu funcionamento em todas as áreas, possui grande dificuldade de mudanças ao ponto de trazer grande sofrimento.

É nesse contexto acima que existe a possibilidade de apresentar os seis principais grupos existentes no TEA, mesmo anão existindo um teste para realizar o diagnóstico do TEA, pois tais diagnósticos para serem concretizados necessitam de uma equipe de multiprofissionais, envolvendo Neuro, Psicólogos, professores, família e cuidadores dessa criança. O sistema de Diagnóstico Manual Diagnóstico e Estatístico de Transtornos Mentais (DSM-V) e Classificação Internacional de Doenças (CID-10) baseiam-se pelos seus critérios comportamentais "A, B, C, D e E", onde o "A", apresenta déficits que persistem na comunicação social e interação social, subdivididos em 1, 2, e 3; O critério "B", apresentam padrões restritos e repetitivos de comportamento, também subdivido em 1, 2, 3 e 4 pelo DSM-V. No critério "C" apresenta os critérios contidos no "A e B", porém junto com o critério "C" que é justamente os sintomas apresentados precocemente; No critério " $\mathrm{D}$ " os sintomas causam prejuízos clinicamente significativos, e no critério "E”, não é tido como deficiência intelectual ou por atraso global, pois não está abaixo do nível geral do desenvolvimento.

\subsubsection{Definição do Autismo Clássico, Transtorno Desintegrativo da Infância, Transtorno Global do Desenvolvimento não Especifico e as Síndromes de Aspeger e Rett}

O Autismo Clássico era classificado com acentuadas dificuldades na comunicação, na socialização, e na interação social, com comportamentos especificos e repetitivos; Transtorno Desintegrativo da Infância, a criança com essa síndrome, após dois anos de vida, a criança começa a perder uma das habilidades sociais, déficits sociais e comunicativas; Transtorno Global do Desenvolvimento não Específico, categoria usada quando há comprometimento grave e global ao desenvolver a interação social, habilidades de comunicação não-verbal e verbal e presença de comportamentos estereotipados. A Síndrome de Aspeger, o indivíduo apresenta feições diferentes em relação as suas ações, o mesmo age mais de forma prudente, moderada, tendo mais empenho em certas áreas do conhecimento, podendo assim por meio desse empenho, despertar mais interesse por certas áreas do conhecimento, e devido isso apresentarem o perfil de Super Dotados, e também apresenta dificuldades de interação social, e características na linguagem (fala), consideradas assim estranhas, esquisitas.

Atraso na fala, desenvolvimento fluente da linguagem verbal antes dos cinco anos. Dificuldade na linguagem mais rebuscada, ecolalia (repetição do que ouvem eco) de palavras ou frases; Interesses restritos escolhem um assunto de interesse. Casos mais comuns é o interesse exagerado por coleções e cálculos; Presença de habilidades não muito comuns, tais como cálculos mentais, memorização de grandes sequências (mapas de cidades), ouvido musical absoluto, entre outros; Incapacidade de interpretar metáforas, mentiras, ironias, frases com duplo sentido; Dificuldades no uso do olhar, expressões faciais, gestos e movimentos corporais, como a comunicação não verbal; Pensamento concreto; Dificuldade para entender ou expressar emoções e dentre outros. (Vilela 2009, P. 27). Já as crianças com Rett têm dificuldades na coordenação motora, crescimento muito lento, dificuldade de se comunicar, de pensar (cognição) e também na interação, e com o passar do tempo tais dificuldades passam a piorar. E em relação à criança com TEA, o mesmo pode ser considerado como um transtorno que afeta o desenvolvimento do cérebro, onde dificulta a parte da socialização e comunicação da criança, tendo dificuldade de interação social, permitindo assim sua entidade específica. 
Com o passar dos anos, o Autismo era visto como problema vivenciado de dificuldade na dinâmica familiar e afetiva, porém esse termo foi mudado, devido a pesquisas fundamentadas, o qual o descreve atualmente como disfunção biológica estrutural ou funcional, alterando gravemente o sistema nervoso, seu desenvolvimento e maturação, no meio científico, a divulgação mais a frente será:

O autismo é uma síndrome presente desde o nascimento, e se manifesta invariavelmente antes dos 30 meses de idade. Caracterizam-se por anormais os estímulos auditivos ou visuais, e por problemas graves quanto a compreensão da linguagem fala. A fala custa a aparecer, e quando isso acontece, notam-se ecolalia, uso inadequados dos pronomes, estrutura gramatical imatura, inabilidades de usar termos abstratos. Há também em geral uma incapacidade da utilização social, tanto da linguagem verbal, quanto da corpórea, ocorrem problemas muitos graves de relacionamento social antes de cinco anos de idade, como incapacidade de desenvolver contato olho a olho, ligação social e jogos em grupos. O comportamento é usualmente ritualístico e pode incluir rotinas anormais, resistências a mudanças, ligação a objetos estranhos e um padrão de brincar estereotipado. A capacidade para pensamento abstrato-simbólico ou para jogos imaginativos, fica diminuída. A performance é com frequência melhor em tarefas que requerem memória simples ou habilidades viso-espacial, comparando-se com aquelas que requerem capacidade simbólica ou linguística. (Organização Mundial de Saúde, p .23, 1984).

Um grande marco aconteceu em relação ao TEA, pois para chamar a atenção da sociedade para essa síndrome, em 2007 a ONU (Organizações das Nações Unidas), instituiu o dia 02 (dois) de abril, como o dia mundial do autismo, possibilitando mais diálogos entre as famílias, profissionais e interessados da área, aumentando assim mais responsabilidades e estudos pelo TEA. Pode-se descrever que houve um aumento de pesquisa sobre TEA, destacam-se estudos realizados na Suécia em 2014, os quais mostram vários fatores, para o aparecimento dessa síndrome como: fatores ambientais, a genética, o nível socioeconômico da família, complicação no parto, infecções sofridas pela mãe e uso de drogas antes e durante a gravidez.

\subsection{Práticas Pedagógicas para o Transtorno do Espectro Autista (TEA)}

\subsubsection{Intervenção Precoce}

Segundo Dunst e Bruder (2002), a Intervenção precoce é definida como uma prática que diz respeito aos serviços, apoios e recursos necessários para responder às necessidades e oportunidades que incentivem a aprendizagem e desenvolvimento da criança com TEA, bem como o apoio as famílias afins de que as mesmas possam desempenha um papel ativo, no desenvolvimento e assistência dessa criança.

Outro aspecto é quanto mais cedo o diagnóstico for feito, melhores serão os resultados, pois o ideal seria uma criança com TEA ser identificada antes dos três anos de idade. Porém, na prática, os estudos científicos mostram que a consulta com um especialista em Desenvolvimento só ocorre por volta dos quatro anos e que o diagnóstico é muitas vezes feito apenas aos cinco anos de idade o que compromete o processo evolutivo.

Nesta perspectiva, para Correia (2005). Uma das abordagens utilizadas na intervenção precoce é a abordagem desenvolvimentista que procura identificar as características autistas que se afastam do que é considerado desenvolvimento normal, de forma a retomar o percurso do desenvolvimento típico que a criança com autismo não seguiu devido às suas dificuldades de interação e comunicação.

Em relação a essa abordagem Prizant (2000) defende um modelo sócio pragmático desenvolvimentista o (DSP) e apresenta o modelo de intervenção Social (SCERT) (modelo de intervenção comunicação-social, regulação emocional, apoio transacional) que vem para promover as habilidades socioemocionais e de comunicação da criança com TEA. 
Nesse sentido, o modelo DSP defende que é preciso focalizar a iniciação e a espontaneidade na comunicação, seguindo o foco de atenção e motivação da criança, ou seja, construir a partir do seu repertório comunicativo atual, através de recursos que façam parte do contexto da criança.

Enquanto, o modelo SCERTS refere-se aos déficits ocultos centrais que afetam as crianças com TEA, que são: os déficits em comunicação e linguagem, relacionamento social, reciprocidade socioemocional, e processamento sensorial. Sua abordagem é voltada para o individualismo, uma vez que o perfil das crianças apresenta características diferentes e as famílias variam em termos de habilidades, recursos e apoio. O tratamento é voltado para estratégias clínicas que envolvem a escola e a família.

Por outro lado, os déficits no relacionamento social e reciprocidade abordada pelas estratégias desenvolvidas pelo modelo (DIR) (modelo desenvolvimentista, de diferença individual, baseado no relacionamento)dos autores Greenspan e Wieder (2000).

Esse modelo enquadra-se também numa abordagem desenvolvimentista e tem como foco possibilitar que a criança conheça a si mesma, a fim de desenvolver suas capacidades linguísticas, sociais, comunicação e pensamento abstrato e lógico.

\subsubsection{Métodos para desenvolvera criança com Transtorno do Espectro Autista (TEA)}

A priori não existe um método específico a ser aplicado no TEA, pois depende das características e comprometimentos de cada criança, uma vez que cada indivíduo é único. Porém, Escolas e Instituições que trabalham com TEA, fazem uso dos seguintes métodos:no sentido educacional, deve-se pesquisar e buscar conhecer cada um, mas sua aplicação deve ser feita por um profissional habilitado, pois este identificará quais métodos, técnicas ou programas serão adequados ao aluno com o transtorno. Atualmente os métodos usados pelas escolas e instituições são:

TEACCH - (Tratamento e Educação para crianças com TEA e crianças com déficits relacionados com a comunicação) é fundamentado na avaliação individualizada centrada na pessoa com TEA e no desenvolvimento de um programa de ensino estabelecido a partir de suas habilidades, interesses (motivação) e necessidades. Adota uma perspectiva holística, levando em conta a relação família/criança. Outro objetivo busca tornar mais amplo as habilidades, além de atuar em sua autonomia para torná-lo o mais independente possível.

ABA - (Análise Aplicada do Comportamento) é feita com a finalidade de identificar habilidades que a criança já domina e ensinar aquelas que ele ainda não domina. As respostas negativas não são estimuladas, pelo contrário, a criança deve trabalhar apenas os comportamentos positivos. No estímulo de conhecimentos já adquiridos, é utilizada a base fundamental na teoria Estímulo - Resposta, ou seja, o individuo é condicionado a reagir, tendendo a repetir as respostas adequadas ao bom desempenho do processo de aprendizagem.

PECS - (Sistema de Comunicação por troca de figuras) sistema de comunicação através de imagem, é um método barato, fácil de aprender e pode ser aplicado em qualquer lugar, inclusive pelos pais em casa. Uma característica deste métodoé que as crianças iniciam o processo de comunicação, ou seja, são elas que iniciam a interação. Eles não aprendem a esperar ou depender dos adultos que podem satisfazê-las. Aprender o PECS tem conseguido grande efeito de reduzir as preocupações voltadas para o comportamento destas crianças, tanto nas escolas quanto em casa.

Diante do exposto, os métodos educacionais acima citados, de cunho visual são de grande relevância para a construção da aprendizagem da criança com TEA, uma vez que, seu pensamento é fragmentado, e pautado na previsibilidade. Por isso, usar o lado visual como recurso de substituição é possibilitar a pessoa com TEA, comandos compreensíveis sobre qual situação ele será exposto. Entretanto, vale ressaltar que mesmo diante dos vários métodos de intervenção, estes não solucionam os déficits, mas os mesmos vêm para somar com todos os trabalhos já pesquisados e comprovados nesta área, que buscam oportunizar melhoria na qualidade de vida da criança com TEA. 


\subsubsection{Materiais Adaptados para uma Inclusão Significativa}

Segundo (Investigação na Escola Inclusiva, 2006). Um sistema educativo só pode ser considerado inclusivo quando reconhece que todas as crianças podem aprender; admite e respeita diferenças nas crianças, nomeadamente a idade, o sexo, a etnia, a língua, a deficiência/inabilidade, a classe social, o estado de saúde ou qualquer outra condição; admite que as estruturas, sistemas e metodologias de ensino têm de atender às necessidades de todas as crianças; não é restrito ou limitado por salas de aula numerosas nem por falta de recursos materiais. Uma escola inclusiva é assim, um tipo de comunidade educativa cujas práticas respondem à diversidade dos seus alunos, atendendo às necessidades emocionais, acadêmicas e sociais que os mesmos manifestam.

Em outros termos Góes (2008), define o material pedagógico adaptado como "ferramenta e não como fim", o qual propicia a interação, convivência, autonomia e independência nas ações, aprendizado de conceitos, melhoria de autoestima e afetividade". Contudo, é necessário o professor ter o conhecimento da diversidade e das características do seu aluno com TEA, para assim definir estratégias de ensino com o objetivo de desenvolver o seu potencial.

Para Baumelet (1998). Uma turma que acolha crianças diferentes terá inúmeros benefícios ao nível do desenvolvimento cognitivo e social, pois tanto as crianças com necessidade educacionais especiais, quanto às demais, se beneficiaram das interações e dos materiais adaptados, favorecendo o desenvolvimento de todos os alunos, sem exceção. Logo, o material adaptado possibilitará aos alunos mais desfavorecidos que avancem impulsionados pela interação social, sob a orientação do professor e com a colaboração dos colegas. Desse modo, muitas das crianças com TEA irão se desenvolvem em função das condições dos materiais adaptado se afetivas que os cercam. Pois o contato das crianças entre si reforça atitudes positivas, ajudando-as a aprender, a compreender, a respeitar e a conviver com as diferenças. "Todas as crianças, sem distinção, podem beneficiar das experiências obtidas no ambiente educacional e dos materiais adaptados" Ferreira (2003).

Ainda na visão de Baumelet (1998). É de suma importância que na construção desse material adaptado para o aluno com TEA, o professor tenha "consciência das dificuldades acadêmicas, comportamentais, sócio emocionais e especifica dessa criança [...] e seja sensível e compreensivo, perante estas". É impreterível que o mesmo adapte as suas práticas a todos os níveis e aptidões, a fim de conduzir todos os alunos, sem exceção, ao sucesso educativo. Dessa forma, o material adaptado deve ser considerado pressuposto para evolução cognitiva e social do aluno com TEA. Porem, ao refletirmos sobre a o importância dos mesmos como facilitadores no processo de ensino - aprendizagem deve-se considerar as contribuições de Vigotsky (1991) que concebe o desenvolvimento nas relações sociais e em seu caráter histórico-cultural por meio da experiência social.

\subsection{A Contribuição do Psicopedagogo (a) no Processo das Práticas de Intervenção da Criança com TEA.}

Nos últimos anos muito se tem falado sobre o papel e as funções do psicopedagogo, uma vez que, a Psicopedagogia é a ciência que estuda o processo de aprendizagem e dificuldades de aprendizagem, logo este estudo veio contribuir para explicar as causas das dificuldades de aprendizagem. Além disso, ela traz consigo o objetivo central de estudar o processo humano do conhecimento o qual perpassa pelos padrões evolutivos normais e patológicos, bem como a influencia (família, escola, sociedade) no seu desenvolvimento.

Nessas perspectivas o olhar do Psicopedagogo em relação aos diferentes deve ser o de buscar descobrir a lacuna entre o Ser aluno e o Ser sujeito, uma vez que, ele enquanto profissional habilitado tem um olhar mais amplo no que se refere ao processo de aprendizagem, bem como consegue perceber o individuo como um todo, envolvendo assim a criança com TEA já que este não pode ser estudado separadamente do físico, cognitivo, social e o emocional.

Nesse sentido entende-se que o olhar do psicopedagogo para os diferentes seja o oferecer igualdade de oportunidades para que os mesmos tenham possibilidades reais de construir seu próprio conhecimento e autonomia dentro de suas 
potencialidades e limites de cada um. Logo, o psicopedagogo dentro da escola torna a inclusão mais eficaz e possível, partindo da perspectiva que todo sujeito é capaz de aprender.

Nesse contexto, a maior barreira que pode haver para uma pessoa com TEA é a "barreira humana" a qual persiste através do preconceito, discriminação e aceitação de lidar com o desconhecido. E é dentro da escola que o psicopedagogo pode propor trabalhos voltados para lidar melhor com essa diversidade, levando professores e alunos a acreditarem que todos são capazes de aprender. Segundo Freire (1996) “[...] E é porque amo as pessoas e amo o mundo que eu brigo para que a justiça social se implante antes da caridade". "Incluir não é fazer caridade, e sim, justiça".

\section{Metodologia}

Visando a complexidade do fenômeno a ser pesquisado e os vários aspectos que o cercam, optou-se pela pesquisa pela pesquisa do tipo exploratório-descritiva com abordagem qualitativa, com método dialético. A escolha por este tipo de pesquisa justifica-se ainda, considerando o nosso objetivo geral que suscita uma metodologia de investigação que dá ênfase à descrição, à reflexão e ao estudo das percepções e práticas dos sujeitos envolvidos na pesquisa (Bogdan \& Biklen, 1994). Considerandose as Práticas Pedagógicas e os métodos como recursos para o desenvolvimento da criança com TEA, buscou realizar um estudo sobre a influência dessas Práticas Pedagógicas e dos métodos no processo de desenvolvimento de sua aprendizagem. Assim, o tipo de técnica metodológica escolhida para esse estudo foi a pesquisa bibliográfica explicativa. Segundo Gil (2010), a pesquisa bibliográfica é elaborada com base em material já publicado. Tradicionalmente, esta modalidade de pesquisa inclui material impresso, como livros, revistas, jornais, teses, dissertações e anais de eventos científicos. (Todavia, em virtude da disseminação de formatos de informações, estas pesquisas passaram a incluir outros tipos de fontes, como material disponibilizado pela internet.).

\section{Resultados e Discussão}

Foi possível perceber que na maioria das vezes, o autismo não é visto como um transtorno desenvolvimento neurológico, e que tão pouco tem-se o conhecimento das ferramentas/recursos para se evoluir uma criança com TEA, na maioria das vezes ainda se cair no velho discurso de que a mesma não consegue aprender. Mediante as leituras foi perceptível que ainda é necessário que professor e sociedade conheçam esse transtorno para que assim, todos tenham atitudes mais sensíveis e acolhedora à essa realidade. Logo, "abraçar" o autismo é se permitir conhecer todos os recursos, métodos e práticas disponíveis que se tenha como forma de inclusão e evolução, só assim, iremos colher frutos posteriormente. É um aprendizado constante quando o ser humano se permite conhecer o mundo singular do autismo. Diante do que foi abordado, evidenciamos que a visão da sociedade, geralmente se volta para os aspectos inerentes à pessoa com Transtorno do Espectro do Autismo, como os déficits presentes no transtorno. Torna-se mais fácil se acomodar, do que permitir avançar em busca de ações significativas. Alguns avanços relacionados ao sujeito com TEA só é possível quando se oportuniza uma interveção precoce com todos os seus recursos (práticas e métodos). A criança com autismo "às vezes, [...] pode expressar a sua gratidão oferecendo uma pedrinha, e manifestar seu amor com um pequeno toque na sua mão. E tenha a certeza de que isso é muito para eles" (Silva et al, 2012, p.92). Entender o autismo é ir além do que olhos podem ver, é trilhar um caminho sem placas de direcionamento, e que apesar das dúvidas, cada caminho trilhado, é um conhecimento construído, e os obstáculos que aparecerem no caminhar irão levar novos saberes. Ressaltamos que quando é reconhecido as necessidades, fica mais acessível a busca por melhores metodologias e formas para desenvolver um trabalho direcionado a singularidade do autista. 


\section{Conclusão}

A experiência que nos foi proporcionada e vivenciada nos levou a construção deste artigo, como também o entendimento de que a educação inclusiva é desafiadora, especialmente quando nos referimos a criança com TEA, pois sua característica especifica exigem maior desempenho e comprometimento nas adaptações das práticas pedagógicas à realidade dessas crianças, uma vez que esta deficiência não tem cura. Todavia, essas práticas e adaptações contribuem para o desenvolvimento de todos seus aspectos oportunizando uma melhor qualidade de vida em todos os seus âmbitos.

Porém, este processo não acontece apenas com a matricula deste aluno, e sim com o atendimento e possibilidades de todas as condições para mantê-lo neste espaço escolar, por isso é necessário refletir que a inclusão perpassa a ideia de uma simples matrícula, ou seja, precisa ser oferecido todos os recursos para que o mesmo consiga se desenvolver, aprender e conquistar seu espaço e respeito não só no ambiente escolar como também na sociedade. Desta forma, percebe-se que ainda existem vários caminhos a percorrer sobre o tema abordado, mas esta pesquisa se constitui em um deles, por isso espera-se que o presente estudo seja fonte de inspiração para outros pesquisadores, dedicada e sensibilizada pelo tema da educação especial, todavia é fundamental a consciência e sensibilidade de que todos envolvidos nesse processo são seres humanos e como tal dotados de um grande potencial a ser explorado, acolhido e respeitado.

\section{Referências}

American Psychiatry Association.Diagnostic and Statistical Manual of Mental disorders - DSM-5. (5a ed.), American PsychiatricAssociation, 2013.

Associação Dos Amigos Da Criança Autista (AUMA). Disponível em: http://www.autista.org.br/. Acesso em 24 maio $2010 . p .17$.

Baumelet, J. J. (1998). Osteologia. En: Nomina AnatomicaAvium (J.J. Baumel, A.S. King, A.M. Lucas, J.E. Breazile ¡r H.E. Evans, eds.). Academic Press, London.

Carr, A. \& Zager et.(2009)Autism and pervasive developmental disorders. In A. Carr.

Correia, O. B. (2005). A Aplicabilidade de um Programa de Intervenção Precoce em crianças com possível Risco Autístico.

Dunst, C. J., \& Bruder, M. B. (2002). Early intervention service coordination models and service coordination practices. Journal of Early Intervention, 28(3), $155-165$.

Ferreira, M. E. C., \& Guimarães, M. (2003) Educação inclusiva. Editora: DP \&A.

Fermino, F. S.; Boruchovith, E.; Diehl, T. L. F. (2001). Dificuldades de aprendizagem no contexto psicopedagógico. Vozes.

Garcia, T., \& Rodriguez, C. (1993). A criança autista. In R. Bautista (coord.), Necessidades Educativas Especiais (pp.249-270). Dinalivro.

Gil, A. C. (2010). Como elaborar um projeto de pesquisa. (4a ed.), Atlas

Góes, R. S. de. O Material Pedagógico Adaptado como Ferramenta e não como Fim: uma Reflexão a respeito da Inclusão de Pessoas com Deficiência NeuroMotora. http://fórum.ulbratorres.com.br/2008/.../PALESTRA\%205\%20- \%20GOES.pdf Acesso em 02/04/10.

Greenspan, S. I., \& Wieder, S. (2000). A developmental approach to difficulties in relating and communicating in autism spectrum disorders and related syndromes. In A. M. Wetherby\& B. M. Prizant (Orgs.), Autism spectrum disorders. A transactional developmental perspective (pp.279-306). Baltimore: Paul H. Brookes.

Improvement Through Research In The Inclusive School, Estratégias e Práticasem Salas de Aula Inclusivas, IRIS 128735-CP-1-2006-1-BE-COMENIUS-C21.

Marques, C. (1998). Perturbações do espectro do Autismo: ensaio de uma intervenção construtivista desenvolvimentista com mães.DissertaçãodeMestrado não publicada. Faculdade de Psicologia e de Ciências da Educação, Universidade de Coimbra

Organização Mundial De Saúde. Classificação internacional dedoenças. (9a ed.), 1984

Prizant, B. M., Wetherby, A. M., \& Rydell, P. J. (2000). Communication intervention issues for children with autism spectrum disorders. In A. M. Wetherby\& B. M. Prizant (Orgs.), Autism spectrum disorders.A transactionaldevelopmentalperspectiv (pp.193-224). Paul H. Brookes.

Vilela, Carlos; Diogo, Sandra; Sequeira, Sara. Autismo e Síndrome de Asperger. Psicologia.com.pt. Portal dos Psicólogos. Instituto Superior Manuel Teixeira

Gomes, Portimão, Portugal, <http://www.psicologia.pt/artigos/textos/TL0140.pdf>. 2013.Fonte: https://psicologado.com/atuacao/psicologia-clinica/a-atuacaodo-psicologo-com-o-transtorno-do-espectro-autista $@$ Psicologado.com

Vigotsky, L. S. (1991). Aprendizagem e desenvolvimento intelectual na idade escolar. In: Vigotsky, L. S. et al. Psicologia e Pedagogia I: bases psicológicas da aprendizagem e do desenvolvimento. (2a ed.). 